\title{
As economias extrativas e o subdesenvolvimento da Amazônia brasileira: contribuições do Prof. Stephen Bunker
}

Maria Célia Nunes Coelho - Professora do Departamento de Geografia da UFRJ Maurílio de Abreu Monteiro - Professor do Núcleo de Altos Estudos Amazônicos da UFPA

\section{Resumo}

Este texto é uma homenagem dos Novos Cadenos do NAEA ao Prof. Stephen Bunker, recentemente falecido. O objetivo geral é refletir sobre a obra do professor, que desempenhou um importante papel na história das idéias sobre a Região Amazônica brasileira, ressaltando o modelo empírico e teórico-interpretativo desse intelectual, elaborado no contexto do debate sobre o desenvolvimento regional no período de 1975 a 2005. O Prof. Stephen Bunker consagrou-se como um brasilianista especialista no exame das "economias extrativas", pelo valor de seu modelo explicativo do subdesenvolvimento das regiões ricas em matérias-primas.

\section{Abstract}

This article is a tribute to Professor Stephen Bunker, who recently passed away. The general aim of this pioece is to analyze the role played by his work in the history of studies about the Brazilian Amazon region. We discuss Prof. Bunker's empirical and theoretical-interpretative model that was elaborated in the context of the debate on the regional development in the period from 1975 to 2005. Prof. Stephen Bunker became well known as a Brazilianist for his study of the extractive regions and for the importance and originality of his explanatory model of the under-development of areas well-endowed with raw materials.

\section{Palavras-chave}

Amazônia, desenvolvimento regional, subdesenvolvimento, matérias-primas, Stephen Bunker

\section{Keywords}

Amazonia, regional development, underdevelopment, raw materials, Stephen Bunker 
A morte do Prof. Stephen Bunker - ex-professor do Núcleo de Altos Estudos Amazônicos (NAEA) da Universidade Federal do Pará (UFPA) e membro do conselho de pareceristas da nossa revista por quase uma década - em 19 de julho de 2005, aos 61 anos, põe fim a intensas atividades de pesquisa, ensino e elaboração teórica focadas na construção de um modelo explicativo da desigualdade de desenvolvimento das "regiões extrativas" da América Latina, ou seja, de economia dominantemente extrativa, conforme sua própria classificação (BUNKER, 1985).

O Prof. Stephen Bunker nasceu em Chicago (Illinois, Estados Unidos), em 1944. Tornou-se mestre em Sociologia pela Duke University (USA), em 1968. Pela mesma universidade, doutorou-se em Sociologia em 1975. De 1973 a 1974, o Prof. Bunker exerceu o cargo de professor visitante na Universidad Del Valle na Guatemala. Nesse mesmo período, o Prof. Bunker participou como conselheiro dos comitês do Department of Sociology and African Studies Program, do programa Women in International Development, e do Center for Latin American and Caribbean Studies. Entre 1975 e 1978, morou na cidade Belém, no estado do Pará, onde atuou como pesquisador e professor visitante do NAEA da UFPA. Entre 1978 e 1984, foi professor do Department of Sociology, na University of the Illinois at Urbana-Champaign. Entre 1985 e 1987, ocupou a função de professor associado no Department of Sociology, na Johns Hopkins University. O Prof. Bunker foi também professor de Sociologia Rural da University of Wisconsin-Madison.

Até a década de 70 do século XX, o Professor dedicou-se aos estudos relacionados à Sociologia Rural, privilegiando temas como "a organização dos pequenos produtores rurais" e "as interações entre a burocracia e os sistemas de poder nas comunidades rurais", tendo como elementos de análise os programas regionais de desenvolvimento na Guatemala (América Central), no Peru (América Andina), em Uganda (África) e no Pará (Brasil). De 1980 em diante, dirigiu seus trabalhos para o exame das conseqüências da implantação dos "pólos de desenvolvimento" (BUNKER, 1989a, 1989b), uma estratégia do $2^{\circ}$ Plano Nacional de Desenvolvimento (1974-1979), aplicada à Amazônia brasileira pelos governos militares de então. A partir daí, apoiado numa perspectiva teórica que combinava a economia política dos recursos naturais e a ecologia, o professor centrou mais claramente seu trabalho na avaliação dos empreendimentos minerários nas economias dominantemente extrativas.

A Região Amazônica brasileira mereceu atenção especial do Prof. Bunker, ao ser por ele apresentada como um exemplo significativo de uma economia extrativa. A Amazônia brasileira constituiu-se, assim, no 
mais importante objeto de pesquisa da obra do Prof. Stephen Bunker sobre as trajetórias comparadas das economias extrativas, histórica e hierarquicamente subordinadas no sistema capitalista. A confrontação das idéias teóricas sobre as trajetórias das economias extrativas no campo amazônico tornou-se dessa forma parte do projeto intelectual desse autor, que fixou residência em Belém no período de 1975 a 1980. Nesse período, não só realizou pesquisas próprias, mas também ajudou a criar uma instituição, o Núcleo de Altos Estudos Amazônicos (NAEA), vinculado à Universidade Federal do Pará. Nessa instituição, o Prof. Bunker ensinou e orientou estudantes da Amazônia brasileira, peruana, venezuelana e colombiana.

Testemunho de uma época que correspondeu a uma nova fase de inserção da região de economia extrativa na economia de mercado em âmbito global, o Prof. Bunker pôde, assim, acompanhar, vivenciar, registrar e interpretar um momento de construção de novas estratégias que pareciam desafiar o modelo centro-periferia até então aplicado às relações desiguais estabelecidas entre países exportadores de matériasprimas e países industrializados.

Nos Estados Unidos, o Prof. Bunker dedicou-se à definição de caminhos teóricos e empíricos que lhe permitiram avançar na elaboração e na divulgação de suas idéias sobre os modelos explicativos da inserção competitiva dos recursos dos países ou regiões extrativas na "economia mundo" (WALLERSTEIN, 1979) e seus impactos nas economias e instituições regionais. Continuou então a orientar teses de estudantes brasileiros e de outras nacionalidades, quer como orientador titular quer como membro de comitês de orientação. De 1999 a 2003, o Prof. Bunker continuou a visitar o Brasil, a ensinar na UFPA e dando prosseguimento aos seus estudos, envolvendo neles pesquisadores como Maria Célia Nunes Coelho e Maurílio Abreu Monteiro. Analisar o projeto intelectual de Bunker não exclui ressaltar a dimensão humana desse autor, que fez inúmeros amigos no Brasil, cativados pelo seu interesse de vê-los avançar em seus projetos individuais e coletivos de compreender a Amazônia de uma forma articulada entre diversas escalas espaciais.

No presente escrito, procuramos apontar algumas das mais relevantes contribuições do Prof. Stephen Bunker para a implantação das dinâmicas de desenvolvimento da Amazônia, sem ter, portanto, a pretensão de esgotar a revisão da importância das idéias ou conclusões (concebidas individual ou coletivamente) do pesquisador para a renovação de um campo de análise concernente à economia política e à ecologia da Amazônia brasileira. 
Em 1985, o Prof. Bunker lançou o livro Underdeveloping the Amazon: Extraction, Unequal Exchange, and the Failure of the Modern State como resultado de suas pesquisas empíricas e de suas reflexões sobre o modelo do qual a Amazônia constituía-se como exemplo. Buscava o autor realizar um balanço dos três séculos e meio de exploração extrativista da Amazônia. Além disso, reuniu nesse mesmo livro ensaios nos quais examinava a natureza e as ações das instituições regionais. Todavia, esse livro nunca foi traduzido no Brasil.

Entre as idéias e contribuições mais importantes do Prof. Bunker, contidas em seu livro de 1985, estão as indicações de que as "economias extrativas" apóiam-se, fundamentalmente, na extração de recursos da natureza mais do que na criação de valor por meio do trabalho; as economias extrativas participam do "sistema mundial" (WALLERSTEIN, 1979), exportando produtos extrativos para as "economias de produção". Conseqüentemente, o fluxo de energia de uma economia extrativa, como a amazônica, para uma economia produtiva, reduz a complexidade e faz crescer a entropia na primeira, enquanto aumenta a complexidade e o poder da segunda. Além disso, os padrões de localização e de acumulação, as trajetórias de desenvolvimento regional e os efeitos ambientais nas economias extrativas são diferentes dos promovidos nas economias de produção.

Tais idéias achavam-se influenciadas pelas teorias do "intercâmbio desigual" de Aghiri Emmanuel (1972) e da "acumulação em escala mundial" de Samir Amin (1974), pela teoria do world system de Immanuel Wallerstein (1979) e pelo arcabouço teórico desenvolvido por Georgescu-Roegen (1971), que decorre sobretudo do esforço para incorporar os princípios da termodinâmica linear - especialmente a noção de entropia - ao instrumental analítico dos processos sociais.

Havia no livro mencionado uma atmosfera pessimista, segundo a qual os desdobramentos e os resultados dos processos das sucessivas explorações capitalistas contribuíram para o subdesenvolvimento da Amazônia. Porém, a abordagem da Amazônia brasileira apresentada pelo Prof. Bunker, cuja importância residiu não só no tratamento da região como um sistema historicamente integrado a uma dinâmica global, mas, sobretudo, na tentativa do autor de criar um modelo histórico interpretativo dos processos de desenvolvimento das economias extrativas em áreas periféricas e distantes das economias de produção (os centros industriais). Dessa forma, com base nesse modelo, o autor justificava o histórico subdesenvolvimento acompanhado do empobrecimento da Região Amazônica. A análise dos fluxos de matérias e energias apresentada pelo autor apoiava-se numa visão integrada das 
relações entre sociedade e natureza física que ele reputou como indispensável para a compreensão da importância dos condicionantes locais na estruturação do espaço global.

Sua idéia de que a crescente escala e a localização remota das empresas de extração mineral na Região Amazônica provocavam rupturas drásticas nas economias e instituições regionais acha-se mais bem explicitada no artigo "Ferro, castanha-do-pará e a luta pela terra no entorno de um projeto de mineração na Amazônia oriental" (2000). Nesse texto, o Prof. Bunker examinou a trajetória histórica das economias extrativas e os impactos econômicos e políticos de empresas de mineração de ferro na reestruturação social, política e econômica local. Assim, a infra-estrutura das modernas indústrias de mineração, de um lado, e a forte migração para as áreas mineradoras, de outro, alteraram dramaticamente o ambiente, limitando dinâmicas socioeconômicas preestabelecidas ou em fase de implantação.

Naquele artigo, o Prof. Bunker analisou a trajetória histórica das "economias extrativas", as mudanças sociais e econômicas e a luta pela terra na passagem do domínio regional da extração da castanha-dopará para a extração do minério de ferro no Sudeste do Pará. Examinou como as empresas mineradoras e a infra-estrutura a elas associadas condicionaram o estabelecimento de economias produtivas, a organização das cidades e do campo. Enfim, sua contribuição principal residiu no levantamento e na valorização heurística de elementos físicos e espaciais na análise das trajetórias sociais, econômicas, financeiras e políticas da região.

Em 1994, o Prof. Bunker, em companhia de Bradford Barham e Denis O'Hearn, organizou o livro States, Firms, and Raw Materials. Nesse livro, o Prof. Bunker abordou os seguintes temas: a) as mudanças sociais, econômicas e espaciais verificadas na escala global, decorrentes do estabelecimento de novas relações espaciais, da diferenciação nos fluxos de materiais e de reordenamentos políticos; b) o sucesso das estratégias das economias de produção (particularmente a japonesa) aplicadas à Amazônia, no intuito de assegurar o acesso ao alumínio metálico, o que acarretou a transferência das indústrias químicas e metalúrgicas para países e regiões ricas em matérias-primas minerais e em potencial energético sem que o modelo global de subordinação dos países extrativistas aos países centrais fosse modificado; c) o insucesso dos empreendimentos historicamente voltados para a extração de matérias-primas, que não conseguiram produzir efeitos de encadeamento para frente ou para trás e de industrialização nas economias extrativas; d) a negligência das elites políticas nacionais e regionais das economias extrativas e a necessidade de 
implementação de uma estratégia tributária que considerasse a renda diferencial da terra aplicada à exploração extrativa, ampliando as possibilidades de captura de renda pelas "economias extrativas". Num cenário mundial marcado pela globalização, o Prof. Bunker examinou as novas estratégias que envolviam grandes empresas, estados nacionais e bancos e que redundaram na formação de parcerias (joint ventures), na concessão de créditos por bancos internacionais, em estímulos para que os países exportadores de matérias-primas arcassem com o custo da infraestrutura necessária à materialização de Investimentos Externos Diretos (IED) (Foreign direct investment (FDI)) e de contratos de compra de longo prazo. Estratégias que afetaram o desenvolvimento econômico e a ecologia das regiões ricas em recursos naturais e mantiveram favoráveis as condições do desenvolvimento do capitalismo global.

No livro de 1994, o Prof. Bunker valorizava elementos como localização, distância, condições topográficas, geológicas, climáticas e biológicas, que proporcionam bases muito importantes para explicar as estratégias sociais e geopolíticas voltadas para a viabilização da extração, transporte e transformação de matérias-primas. A abordagem representava um diálogo entre economia política, ecologia e geografia econômica. A ecologia política considera que a formação geológica, a localização geográfica, a topografia das áreas de ocorrência dos recursos naturais, as propriedades físico-químicas dos recursos naturais, as estruturas de propriedade, de produção e de consumo implicam o estabelecimento de relações que determinam a organização e a operação da extração de matérias-primas. Dessa forma, o Prof. Bunker teve o mérito de trazer para o campo de análise da inserção da Região Amazônica na economia mundial a discussão das vantagens competitivas herdadas e criadas (com base na qualidade do minério e no custo competitivo de transporte), fundamentais para o exame das estratégias atualizadas da nova incorporação de periferias ricas em recursos naturais ao sistema mundial. De acordo com esse modelo, espaço amazônicos foram incorporados com base na qualidade dos minérios encontrados, na topografia, no clima, na hidrografia, na estruturação de arranjos institucionais que reduziram custos de extração, transporte, transformação e exportação. O autor ajudou, assim, a explicar como a formação de parcerias (estimuladas pelos Estados nacionais consumidores de matérias-primas) e as guinadas das políticas públicas destinadas à criação de condições de desenvolvimento da economia de escala, no caso do alumínio e do ouro, provocaram impactos em áreas remotas, ecologicamente frágeis e pouco conhecidas da Floresta Amazônica. 
Para o Prof. Bunker, a experiência brasileira demonstrava que o triunfo das estratégias das "economias de produção" minou a possibilidade de verticalização da produção mineral na região. A descentralização do poder estatal com a Constituição de 1988, suscitou grandes expectativas em todos os setores da sociedade. No entanto, medidas como a lei que isentou os exportadores de matéria-prima e de produtos semi-acabados do pagamento do principal imposto aos estados exportadores de matérias-primas - eliminaram gradativamente a possibilidade de os estados mineradores conquistarem autonomia para tributar bens extrativos. Essas idéias eram recorrentes no trabalho do Prof. Bunker. Podem ser encontradas nos textos "Extração e tributação: problemas de Carajás", de 1986, e "Notas sobre a renda do solo e a tributação no Pará", de 2001, entre outros. Particularmente, o Prof. Bunker, ao abordar o tema economia dos recursos naturais, clamava pela necessidade de se repensar e de se ampliar as compensações pecuniárias dos estados de "economias extrativas" por garantirem o acesso aos recursos que se encontram nos seus territórios. Analisando a Lei Complementar 087, de 1996, o Prof. Bunker chegou à conclusão de que essa lei, ao isentar os exportadores de matérias-primas e produtos semi-acabados do pagamento do Imposto sobre Circulação de Mercadorias e Prestação de Serviços (ICMS) -, comprometeu a autonomia dos estados ricos em recursos minerais. Examinando a legislação que estabeleceu a Compensação Financeira pela Exploração de Recursos Minerais (CFEM), considerou uma importante conquista da Constituição de 1988, por compensar os estados pela extração de um bem que não mais estará à disposição da sociedade, constatou, entretanto, que a legislação não leva em consideração as diferenças no teor relativo de diferentes depósitos em comparação com outras fontes da matéria-prima. Por outro lado, a legislação levou em conta a diferença existente em termos econômicos e tributários entre um bem produzido por capital e trabalho e outro cuja valoriação vincula-se, sobretudo à existência de pré-condições de ordem natural. Segundo o Prof. Bunker, as restrições tributárias decorrentes de políticas patrocinadas por organizações internacionais, particularmente o Fundo Monetário Internacional, deixaram o estadomembro da Federação que exporta, sobretudo commodities minerais, ainda mais dependente do Estado nacional. Nesse caso, a contribuição do Prof. Bunker consistiu em examinar os mecanismos financeiros e políticos adotados pelo Estado brasileiro e pelos estados da Federação no contexto da globalização, realizando a contabilidade das finanças, decompondo os sistemas que regem as estruturas da economia política de estados federados mineradores. 
No texto "Matter, space, time, and technology shape globalization: finding the world-system in the Amazon", de 2002, que faria parte de um novo livro, intitulado Globalization and the race for resources (em elaboração naquele momento, mas com publicação prevista para janeiro de 2006), escrito juntamente com o Prof. Paul Ciccantell (Professor Associado de Sociologia na Western Michigan University), o Prof. Bunker buscou afinar suas reflexões a fim de integrar elementos ecológicos e sociopolíticos às análises econômicas fundamentadas em estudos comparativos da extração e produção das indústrias mínero-metalúrgicas e de suas conseqüências para as economias das regiões ou dos países ricos em matérias-primas, porém dominantemente explorados pelas economias produtivas.

Nesse novo livro, o Prof. Bunker refletiu ainda sobre a tendência contemporânea de considerar o espaço como um produto social apenas e insistiu na importância da localização, da topografia, das características físicas do minério, etc. para se entender a inserção competitiva no sistema mundial de "regiões extrativas". Indicava, assim, como tais elementos afetaram a reprodução do capital que, por sua vez abarcam organizações tecnológicas, logísticas, demográficas, econômicas, sociais e políticas. Com seu esquema analítico, pretendia explicar a integração ao sistema mundial das periferias ricas em matérias-primas, distantes dos centros geográficos da indústria mundial, e a emergência de novas estratégias para subordinar exportadores periféricos de recursos naturais, num jogo com regras modificadas. Dessa forma, a análise das vantagens locacionais ou das vantagens competitivas naturais e criadas (com base na qualidade do minério e no transporte) foi incorporada na sua matriz analítica e vista como determinante para explicar os novos mecanismos de integração da Amazônia ao mercado mundial de alumínio.

Em relação ao conjunto da obra do Prof. Bunker, podemos ressaltar que suas contribuições ajudaram a desfazer equívocos e armadilhas teórico-interpretativas, responsáveis por discursos desenvolvimentistas e tentativas estratégicas de modernização da Amazônia oriental brasileira, que acalentaram esperanças em diversos segmentos sociais, mas não se concretizaram. Apresentamos abaixo algumas dessas contribuições:

a) A de se interpretar o desenvolvimento da região a partir de dinâmicas locais/regionais, desconsiderando a complexidade sistêmica que envolve parâmetros diversos. As dinâmicas presentes na Amazônia surgem da combinação de restrições regionais e globais. O Prof. Bunker chamava a atenção para o 
equívoco recorrente em análises que têm dificuldade de articular as dinâmicas locais com as globais. Denunciava a ausência de análises interescalares que enfatizem as mudanças na estruturação do sistema mundial e as alterações nas determinações sistêmicas que ensejam a subordinação das regiões periféricas ricas em matérias-primas às regiões centrais.

b) A de que os países e as regiões exportadores de matériasprimas poderiam adquirir o controle soberano sobre seus próprios recursos.

c) A de se considerar que a captura de renda, a partir da tributação, de atividades extrativas deve assumir papel de destaque nas estratégias de desenvolvimento de regiões ricas em matérias-primas - o que não significa deixar de reconhecer que estas tentativas estratégicas vinculadas a políticas tributárias apresentam limitações. Na verdade, elas podem ser em grande parte atropeladas por restrições derivadas de dinâmicas globais. Um exemplo disso foi a pressão para que se retirasse dos estados federados brasileiros a possibilidade de tributar as firmas exportadoras de matérias-primas e de produtos semi-acabados.

d) A de que os estados federados ao enfatizarem a verticalização e negligenciarem alternativas para a diversificação produtiva, não vinculando a diversificação apenas a uma eventual verticalização da produção mineral, partindo de um produto extrativo, mas de incorporar impulsos que possam advir da exportação de commodities para outros segmentos da economia da região extrativa.

e) A de se considerar o espaço apenas como um produto social como fazem David Harvey (1982, 1989) e Milton Santos (1991, 1992). Para o Prof. Bunker, examinar os efeitos do local e do global requer a consideração do espaço como algo materialmente diferenciado pela topografia, pela hidrografia, pelo clima e pela distância absoluta entre os lugares. Nesse sentido, combinava a análise dos elementos físicos do espaço com o exame da organização dos processos produtivos e da estruturação social e espacial no espaço amazônico.

f) A de se considerar a noção da renda da terra, aceita até pelos liberais, como um dos fundamentos da política tributária de estados exportadores de bens minerais. No caso brasileiro, há uma ausência completa da aplicação da "renda da terra" na remuneração dos estados mineradores. Existe uma "renda da 
terra" paga ao estado minerador? A resposta a essa pergunta leva à análise da reduzida autonomia decisória e fiscal do estado federado. A não-tributação adequada das atividades cuja lucratividade assenta-se no uso das vantagens competitivas herdadas faz com que lhes faltem recursos financeiros para incentivar a diversificação da produção. Para o Prof. Bunker, diante das evidências históricas e políticas, os estados federados deveriam incluir fortes elementos da renda diferencial da terra na sua política tributária.

Evidentemente, não obstante a influência que o modelo interpretativo do Prof. Bunker pode ter exercido sobre os países e as regiões extrativistas, sua perspectiva analítica comporta críticas, cuja identificação pode vir a contribuir para a elaboração de novas possibilidades de investigação. Nesses termos, a sua produção tem pelo menos quatro pontos críticos que ensejam, simultaneamente, a crítica e a contribuição de caminhos analíticos alternativos.

A primeira crítica pode ser dirigida ao modelo analítico de ciclos adotado pelo Prof. Bunker. Os estudos das relações internacionais, fundamentados nos "ciclos" da economia, levaram o Prof. Bunker a examinar como, a cada ciclo sistêmico de acumulação em âmbito global, correspondeu uma reorganização econômica, social e política na Amazônia, em condições subordinadas à economia global. Isso resultou numa visão simplificadora de que não há atores locais e nacionais capazes de impulsionarem mudanças que, por sua significação e importância, possam concorrer para a alteração de determinações sistêmicas que servem de parâmetro para a reprodução do sistema como um todo. O Prof. Bunker, portanto, ao ajudar a construir uma história econômica e social da Amazônia, baseada no modelo de ciclos econômicos, reforçou os esforços para explicitar determinações sistêmicas em termos planetários. Todavia, o Prof. Bunker, ao privilegiar, em sua análise, a explicitação das determinações sistêmicas estabelecidas em escala planetária, não dava a atenção necessária a dinâmicas nacionais, regionais, locais que, em alguma medida, constituem forças que contraarrestam determinações sistêmicas, podendo inclusive subvertê-las. Dessa forma, os modelos propostos pelo Prof. Bunker no que tange à organização social associada à extração da borracha, à extração da castanha-do-pará e à extração de minérios permitem compreender o porquê do fortalecimento, por políticas públicas locais, regionais e nacionais, das determinações sistêmicas mais gerais. O escopo analítico é, porém, muito limitado para dar conta das dinâmicas e dos processos sociais em âmbito nacional, regional e local, que contradizem as deter- 
minações sistêmicas. O trabalho do Prof. Bunker pode, assim, dar a impressão de que as determinações sistêmicas são tão rígidas que tornam o devir do sistema mundial previsível, quando na verdade ele próprio reconhecia que lidava com um sistema que conta com determinações, sem, entretanto, ser previsível. Isso sugere que se busque o aprofundamento das análises multiescalares (articulações entre escalas), que se supere a visão de ciclos econômicos extrativos, por meio do estudo das interpenetrações das mudanças (mundiais, nacionais, regionais e locais) que determinam as relações que lhes são subjacentes e são por elas dialeticamente determinadas. O Prof. Bunker criou essa pista, em seus estudos mais recentes, quando buscava examinar os modos pelos quais o local estrutura e organiza o sistema mundial. Todavia, não deu a merecida atenção às relações sociais locais.

Uma segunda crítica que se pode dirigir às análises desenvolvidas pelo Prof. Bunker é a insistência na abordagem do caráter de "enclaves" atribuído às atividades minerais em regiões periféricas, embora o seu trabalho ressalte alguns efeitos espaciais reestruturadores da mineração. A superação dessa fragilidade requer que se aprofundem os estudos das interações entre a mineração e as dinâmicas sociais e políticas e que se explicitem as relações entre movimentos migratórios, mobilidade e mobilização da força de trabalho, atração e remuneração da força de trabalho local e regional, mudanças do agrário e do urbano e as atividades extrativas. A adoção da noção de enclave conduz a uma armadilha teórica associada ao mito de que os efeitos da mineração são localizados e de que não há uma estruturação social e espacial relevante e dela decorrente. Superar esse entrave analítico significa valorizar o papel das minerações como condicionantes da organização das cidades e do campo. Dessa forma, a mineração pode ser vista não como um enclave, mas como um "atrator" modelador da organização demográfica, social, econômica e política.

Tais considerações críticas, se elas têm alguma validade, não têm o intento de reduzir a importância da produção do Prof. Bunker. Justamente pela qualidade de sua obra, convém mais apontar o discutível do que se deter, tão-somente, no enaltecimento dos escritos do Prof. Bunker. A contribuição do Prof. Bunker para o desenvolvimento do pensamento contemporâneo sobre a Amazônia foi e continua a ser relevante, sobretudo no que diz respeito ao seu rompimento com os ideais desenvolvimentistas de verticalização da indústria mineira nos países ou nas regiões ricas em matérias-primas demandadas pelas economias produtivas. Todavia, ela poderá ser mais importante quando outros pesquisadores, dialogando com o modelo de Bunker, aprofunda- 
rem os estudos sobre a exploração de recursos naturais, as políticas tributárias e o desenvolvimento regional. Isso responde ao ideal do Prof. Bunker de treinar pesquisadores críticos e preparados para fornecerem subsídios analíticos, considerando que a mobilização social, o que, na visão dos autores deste texto, constitui-se em uma importante força, capaz de estabelecer alternativas tributárias que favoreçam o desenvolvimento diversificado da Amazônia.

Finalmente, não poderíamos deixar de exaltar a dedicação do Prof. Bunker aos estudos amazônicos e seu papel de formador de recursos humanos capacitados para refletir sobre a sempre instigante realidade amazônica e interpretá-la. Por tudo isso, deixamos aqui registrado o privilégio da passagem desse acadêmico pela Amazônia brasileira. Somos particularmente gratos ao Prof. Bunker por sua importância em nossa formação, pela sua competência e pela sua dedicação e amor ao Brasil e à Amazônia. 


\section{REFERÊNCIAS}

AMIN, Samir. El desarollo desigual: ensayo sobre las formaciones sociales del capitalismo perifério. Tradução de Nuria Vidal. Barcelona: Editorial Fontanella, 1974.

BUNKER, S. Underdeveloping the Amazon: extraction, unequal exchange, and failure of the modern State. Champaign: University of Illinois Press, 1985.

. Extração e tributação: problemas de Carajás. Pará Desenvolvimento, Belém, n. 19, p. 11-12, jun. 1986.

Notas sobre a renda do solo e a tributação no Pará. Papers do NAEA, Belém, n. 159, 2001, 7p.

Staples, links, and poles in the construction of regional development theories. Sociological Forum 4, n. 4, p. 589-609, dez. 1989a.

The eternal conquest. In: NACLA Report on the Americas, $23 \mathrm{n}$. $\overline{1, \text { p. } 27}-40,1989 b$.

Natural resource extraction and regional power diferentials in a global economy. In: ORTIZ, S.; LEES, S. (Ed.). Understanding economic process. Lanham: University Press of America, 1992. p. 61-84.

; BARHAN, B.; O'HEARN, D. States, firms, and raw materials. Madison, Wisconsin: The University of Wisconsin Press, 1994.

; CICCANTELL, P. Globalization and the race for resources. The Johns Hopkins University Press. Publicação prevista para janeiro de 2006.

; O'HEARN, D. Strategies of economic ascendants for access to raw materials: a comparison of the U. S. and Japan. In: PALAT, R. (Ed.). Pacific Asia and the future of the world system. Westport, Conn.: Greenwood Press, 1992. p. 83-102.

EMMANUEL, A. Unequal exchange. London: New Left Books, 1972.

GEORGESGU-ROEGHEN, Nicholas. The entropy law and the economic process. 4. ed. Cambridge, London: Harvard University Press, 1971.

HARVEY, D. The limits to capital. Chicago: Chicago Press, 1982.

The condition of postmodernity. Oxford: Basil Blackwell, 1989.

SANTOS, M. Metamorfose do espaço habitado. São Paulo: Hucitec, 1991.

Espaço e método. São Paulo: Nobel, 1992.

WALLERSTEIN, I. The capitalist world economy. Cambridge: Cambridge University Press, 1979. 